\title{
A APROPRIAÇÃO DA CULTURA PELO TURISMO, A REVALORIZAÇÃO E A RESSIGNIFICAÇÃO DAS IDENTIDADES CULTURAIS
}

\author{
LUANA NUNES MARTINS DE LIMA \\ Universidade Federal de Goiás
}

\section{Introdução}

No atual momento de reprodução do capital, no qual o turismo tem se colocado como uma das atividades econômicas de maior geração de receita, a cultura é capturada pela lógica do valor de troca, agregando valor aos patrimônios materiais (históricos ou não), às práticas e manifestações culturais, tornando-os matéria-prima para a indústria do turismo e do lazer e interferindo direta ou indiretamente no modo de vida das comunidades.

De acordo com Beni (2003, p.37), o turismo pode ser conceituado como um "elaborado e complexo processo de decisão sobre o que visitar, onde, como e a que preço. Nesse processo intervêm inúmeros fatores de realização pessoal e social, de natureza motivacional, econômica, cultural, ecológica [...]". Esses fatores ditam a escolha dos destinos, dos meios de transporte, do tipo de hospedagem, do tempo de permanência, que favorecem a existência da multiplicidade de empresas destinadas ao setor.

De uma forma geral, o turismo globaliza culturas, consolida políticas públicas, cria e ocupa novos espaços e lugares, amplia o fluxo de pessoas, serviços e mercadorias. Pode-se afirmar que cinco eixos-base aglutinam todo o pensar sobre a condição atual do turismo no mundo, sendo eles: o desenvolvimento econômico, a preservação da biodiversidade, a diversidade cultural, as condições para a paz e o desenvolvimento social.

Uma alternativa de turismo muito difundida atualmente é o "turismo de base comunitária", que se enquadra na categoria de turismo sustentável. O turismo comunitário se contrapõe ao turismo de massa, requerendo menor densidade de infraestrutura e serviços, e busca valorizar uma vinculação situada nos ambientes naturais e na cultura de cada lugar. Não 
se limita a percorrer rotas exóticas, distintas daquelas do turismo de massa. Trata-se de um outro modo de visita e hospitalidade, diferenciado em relação ao turismo massificado, que valoriza pequenas cidades e povoados, as singularidades e gêneros de vida distintos que os constituem. Esse tipo de turismo permite que a comunidade local tenha participação na gestão e na renda advinda com o turismo. Contudo, não deixa de estar submetido à problemática que o artigo pretende tratar.

Irving (1998) explica que a indústria do turismo tem se implantado em grande velocidade e magnitude, especialmente em regiões menos favorecidas sob a ótica socioeconômica, mas privilegiadas com relação ao seu patrimônio cultural. Esse avanço do turismo, contudo, nem sempre ocorre a favor das populações locais e, frequentemente, é responsável por fenômenos significativos de exclusão social, descaracterização cultural e degradação ambiental.

As consequências de tal expansão do turismo são as grandes alterações na dinâmica da comunidade receptora, refletindo em mudanças nos usos e costumes, na divisão social do trabalho, no relacionamento interpessoal, sobretudo no familiar, muitas vezes, sem nem sequer haver um contato realmente interativo com os turistas.

A existência de lugares, cujo construto social desperta a sensibilidade de visitantes por sua história, memória, paisagens, modos de vida e de produção dá concretude ao estabelecimento do chamado "turismo cultural".

Barretto (2000) entende por "turismo cultural" todo turismo em que o principal atrativo se enquadre em algum aspecto da cultura humana, podendo ser a história, o cotidiano, o artesanato, as manifestações culturais ou folclóricas, como festas e festivais, peregrinações ou outro dos inúmeros aspectos que o conceito de cultura abrange.

É importante ressaltar que vivemos em uma era em que tudo é cultural e tudo pode se tornar patrimônio, muitas vezes, por razões políticas, particularistas e mercantis. Na tentativa de esclarecer como a indústria cultural, através dos processos contemporâneos de globalização econômica, se relaciona com as localidades e as formas culturais num processo que resulta em sua intensa mercantilização, Costa (2010) parte de uma concepção simbólica de cultura. Ele define a cultura como um padrão de significados incorporados nas formas simbólicas e materiais, entendendo-a como: 
[...] criação, reflexividade e criatividade que se exerce com a necessária relação com o território, materializando-se de alguma forma, entendida de alguma maneira. Sobre ela, então, materializada ou não no território, repousa a tendência dialética da construção e da desconstrução dos lugares, da revaloração da paisagem, na sociedade contemporânea permeada pela própria reprodução do dinheiro no território, produzindo o real espetáculo da sociedade (p. 88).

As culturas se transformam e uma nova tendência de apropriação do espaço estabelece-se nos lugares na busca por assegurar uma visibilidade e um conjunto de práticas que valorizem esses lugares.

É da apropriação da cultura pelo fenômeno do turismo que o presente artigo pretende tratar, dando enfoque ao chamado culturalismo expresso nesta fragmentação da era pós-moderna, que dá abertura a questões étnicas, religiosas e outras expressões identitárias. Nessa era atual, as emoções, a subjetividade, o instinto, o místico, o esotérico, a busca por novas experiências e sensações marcam o modo de vida e se refletem em muitas áreas socioeconômicas, incluindo o turismo.

\section{Cultura e identidade: produtos ressignificados e revalorizados pelo turismo}

Segundo Claval (2008), os estudos culturais com abordagens diretas ao indivíduo, à subjetividade e à experiência vivida se desenvolveu a partir dos anos 1970, com a descoberta da fenomenologia e a nova curiosidade pelo sentido dos lugares. Para o autor, esses estudos trouxeram novas perspectivas sobre a variedade do mundo e sobre o modo como ele é percebido e valorizado.

A difusão dos estudos que valorizam a cultura e põem em foco os processos culturais e socioculturais partindo do indivíduo, gerou mudanças profundas no olhar das pessoas com relação ao que é do outro. A curiosidade e interesse na descoberta, na iniciação, na educação e no espírito de aventura foram dando origem a um novo mercado.

O turismo, como sendo a atividade do uso do tempo livre e do ócio, na busca do prazer individual e imediato, conforma-se como a ocasião ideal para o exercício dessa cultura pós-moderna. As verdadeiras motivações e o contexto psicológico e social dos viajantes explicam como 
o consumo, especialmente por cultura, tem elevado-se a um nível tão sobrejacente.

Além disso, o avanço de uma única cultura hegemônica que se impôs nas últimas décadas na música, no vestuário, na alimentação, nas formas de lazer e de consumo em todas as partes do mundo, torna raras as populações tradicionais que ainda conservam traços originais de sua cultura e identidades que lhes são próprias, favorecendo o interesse pelo que é diferente da maioria.

Para Bonnemaison e Cambrèzy (1996, apud HAESBAERT, 2007), vivemos sob uma "lógica culturalista" ou "pós-moderna" de base identitária que estabelece o território primeiramente como um valor, que produz uma relação forte, ou mesmo uma relação espiritual com nossos espaços de vida. Os lugares são o cenário onde os territórios se formam, criando, por sua vez, identidades culturais. Fazendo relação com a premissa desses autores, percebemos que as comunidades onde o turismo se desenvolve possuem um legado cultural, carregado por uma dimensão simbólica, e exercem uma forma de "controle simbólico" sobre o espaço onde vivem.

Nisto consiste o lugar turístico: ser um território em constante disputa, pois estando sob esse controle simbólico das comunidades que o constroem, são apropriados ao mesmo tempo pela atividade turística, que o reordena conforme seus próprios moldes.

O turismo deve ser analisado enquanto um fenômeno econômicocultural moderno dinamizado por uma sociedade de consumo e, portanto, essa análise deve se estender para além da dimensão material do espaço. Sua produção, reprodução, fragmentação e homogeneização no/do espaço através das novas espacialidades da vida social, material e simbólica, por vezes produzem lugares turísticos subordinados aos atores hegemônicos, gerando uma desordem desmedida na estrutura social.

Em uma abordagem sobre a disputa de território, Chaveiro (2008) sintetiza como alguns atores que participam dessa disputa transformam a cultura e sua potencialidade em negócio para lazer e turismo, adequando a cultura local à demanda por consumo. Com isso, "as festas, as temporadas e eventos criados se ajustam à criação de um desejo baseado na performance, no narcisismo, na corpolatria, na autoajuda, na institucionalidade religiosa e outros" (p. 85). 
Para Almeida (1998), o lugar turístico presta-se, principalmente a essa condição que pode ser considerada híbrida: lugar, espaço vivido e de existência para a população local e lugar de representações e imagens para os turistas. Assim, o lugar turístico é, sobretudo, espaço de alteridade, é onde o visitante e o visitado se encontram, se observam, se comparam, criando opiniões sobre si e sobre o outro. "Em si o lugar turístico não existe. Ele é uma invenção pelo e para o turismo, invenção que é feita no bojo de uma expectativa alimentada pela fantasia, pela busca de ação, nostalgia e exotismo" (p.125).

Almeida (1998) ainda afirma que o lugar deve corresponder às imagens e ao imaginário daquele que é turista, o que supõe um desvio do uso tradicional do lugar. "É o olhar extasiado, do 'outro', do forasteiro, admirando paisagens a que atribuem valor, [...] parte de seu próprio conjunto de valores e que, associado aos interesses do lucro, pela mídia, postais e guias de viagens, inventam o lugar turístico" (p. 125).

Assim, o lugar turistificado tem a sua população local transformada em "a outra", aquela que muitas vezes impede, incomoda o turismo, tornando-se estranha em seu próprio lugar. O lugar, portanto, tanto manifesta como oculta a realidade.

Almeida (2004) também trata do contraste entre desenvolvimento turístico e desenvolvimento local, enfatizando que a construção do espaço turístico se dá com a desconstrução do lugar. As transformações do ambiente e das relações sociais, bem como do patrimônio cultura, elementos que antes permitiram a existência desse lugar, são em "função do outro", para a conservação do atrativo e não para a valoração local, sendo esses elementos desterritorializados para serem exclusivamente revalorizados pelo turista.

Nessa lógica, as inovações, os eventos culturais e os espetáculos são latentes, muitas vezes resgatados ou recriados, tornando-se o "cartão postal", o principal convite à visita. A mídia promove o encontro entre a cultura e a mercadoria, construindo imaginários numa difusão de imagens superficiais que tentam reproduzir o real num processo mercantilizador das singularidades culturais.

O turismo pode interferir na maneira como as comunidades locais se sociabilizam, percebem e concebem seu ambiente. As manifestações culturais são um importante fator de sociabilidade e percepção de seu próprio meio, bem como um elemento que confere identidade ao lugar. 
Bezerra (2007, p.69), ao destacar o papel da festa no processo de (re)afirmação das identidades locais, traz como problemática a mercantilização da cultura, fazendo a seguinte consideração:

Esse processo de mercantilização da cultura tem tido um
rebatimento especialmente nas cidades, desencadeando
investimento nas políticas de revitalização de centros
históricos e na organização de festas - que têm assumido a
característica de grandes espetáculos - reafirmando, desse
modo, particularidades/singularidades regionais e locais, o
que implica uma (re)elaboração das identidades que, não
raramente, são vendidas no mercado de cidades.

Araújo (1998) levanta ainda outro argumento sobre essa relação turismo - comunidade local. Fala-se muito da possibilidade de o turismo promover a integração entre os povos. Porém, segundo o autor, na prática, o que acontece é o isolamento do turista, que vivencia apenas os locais "pasteurizados" para ele, livre de mendigos, sujeira, ou das próprias pessoas "comuns" de um determinado lugar.

Nos locais turísticos há uma oferta e uma demanda onde são praticados os maiores preços, afastando, assim, a comunidade local. Portanto, não há integração construtiva para as pessoas. Alguns aspectos da vida da população aparecem nas apresentações aos turistas, mas quando isso ocorre, é de forma estilizada ou deturpada, como é o caso dos elementos das danças populares presentes em quase todos os "shows" destinados à turistas. Sobre isso, considera-se importante outra colocação de Bezerra (2007, p.78):

Esse processo de espetacularização se situa nesse momento histórico da dinâmica capitalista em que o uso da imagem e a intensificação do consumo assumem uma centralidade, estando intrinsecamente relacionados, pois a aceleração do tempo de giro na produção da volatidade envolve a manipulação do gosto e da opinião. É a partir desse quadro [...] que a publicidade e as imagens da mídia passaram a ter um papel mais integrador nas práticas culturais, tendo assumido agora uma importância muito maior na dinâmica de crescimento do capitalismo.

$\mathrm{O}$ apelo pela cultura, ou pelo culturalismo, coloca-se como cerne das ações midiáticas e dos empreendimentos turísticos, que se utilizam das 
imagens e representações da realidade de um lugar para criar no imaginário coletivo a valorização e anseio por estar no mesmo.

$\mathrm{Na}$ lógica do turismo é aceitável e até necessário impor alguns atrativos, recriar ou transformar algo em espetáculo, fazer modificações no que é original, para agregar valor, atribuir um sentido exótico ou que cause maior interesse. No entanto, essas ações resultam no estabelecimento de uma nova estrutura socioespacial e na ressignificação de símbolos identitários que têm um sentido na memória coletiva local.

Com a turistificação o lugar assume novas formas e funções, afetando essencialmente as dimensões materiais e simbólicas da sociedade. Em uma abordagem sobre os processos produtores de imagens coletivas e representações das especificidades culturais locais, Bustos Cara (1996) apresenta cinco momentos que resultam da relação entre a população local e os estímulos da atividade turística que constroem um mundo imagético e de representações. Nessas imagens e representações, que dão certo sentido ao atrativo turístico, a população local reinventa-se, constituindo-se em o que o autor denomina "população artificial", à medida que vai se modificando, ou se ressignificando, para atender à demanda do turismo.

No primeiro momento Bustos Cara (1996) apresenta a população local, que produz as imagens, e o turismo ainda em processo de consolidação através dessas imagens criadas. No segundo momento, o estabelecimento de um envolvimento entre população local e população artificial, criado pelas novas relações econômicas turísticas. No terceiro momento a população local distancia-se da população artificial, perdendo seus referenciais locais. No quarto momento a população local toma consciência de classe e de expressão política e busca unificar a sociedade artificial criada. Já no quinto e último momento, estabelece-se a população artificial sem contato com a autêntica.

Percebe-se, nos momentos descritos pelo autor, a busca pela originalidade e raízes culturais, motivo pelo qual a própria população local cria imagens que a legitimam. Como foi dito anteriormente, surgem a imposição de alguns atrativos, a recriação e a transformação de práticas ou manifestações, que antes faziam parte do simples cotidiano, em espetáculo, bem como novas narrativas, novas fábulas e novas imagens dos lugares. Tudo isso direciona a constituição de uma sociedade que, por sua vez, nega ou ignora as funções, os costumes e as paisagens locais, objetos de apropriação turística. 
Em contrapartida, Luchiari (1998), abordando essas novas formas e funções assumidas com a turistificação do lugar, nos leva a ver o lugar turístico como um elemento dinâmico, onde podemos presenciar o movimento dialético num processo de construção de

[...] novas formas contemporâneas de espacialização social,
por meio das quais estamos construindo novas formas de
sociabilidade, mais híbridas e mais flexíveis. [...] estabelece-
se uma relação entre antigas paisagens e velhos usos e novas
formas e funções, impulsionando a relação do lugar com o
mundo, que o atravessa com novos costumes, hábitos,
maneiras de falar, mercadorias, modo de agir [...]. Assim
também, a identidade do lugar é constantemente recriada,
produzindo um espaço social híbrido, onde o velho e o novo
fundem-se dando lugar a uma nova organização socioespacial
(LUCHIARI, 1998, p. 17 apud FRATUCCI, 2000, p. 129).

Barreto (2000) indaga se há alguma manifestação humana, atualmente, que não se transforme, de alguma maneira, num bem de consumo, ora em virtude da modernização imposta pela indústria cultural, ora pela globalização da economia, que aspira a igualar todos os espaços sob os mesmos cartazes e logotipos. As principais críticas da autora referem-se à transformação do legado cultural em bens de consumo.

Barretto (2000) argumenta que para alguns antropólogos e historiadores, a preservação da identidade partiu da exigência do mercado turístico internacional, uma vez que os turistas provenientes, em sua maioria, de países ricos, buscam, de certa forma, o "paraíso perdido". As comunidades receptoras, justamente por serem menos desenvolvidas e, consequentemente, menos ricas, mantêm essas características rotuladas de "autenticidade local".

Surge uma necessidade de mercado com essa busca por elementos característicos e diferenciais de cada cultura. A cultura autóctone se torna matéria-prima para a criação de um produto turístico comercializável e competitivo no âmbito internacional. Para Barretto (2000, p.48), "o legado cultural, assim transformado em produto para o consumo, perde seu significado. A cultura deixa de ser importante por si mesma e passa a ser importante por suas implicações econômicas".

Assim como o mercado turístico divulga e desperta a busca por essas novas experiências culturais, alavancando esse segmento e alterando 
o perfil do turista, as populações locais receptoras também se alteram, se adaptam, criando meios de sobrevivência ou até de resistência. Acreditando ser uma boa oportunidade e se aproveitando de alguns benefícios, essas populações favorecem o desvio da utilização tradicional do local, a recriação contínua e o embelezamento do local em prol da estética do olhar do turista. Segundo Almeida (2003, p. 15), o lugar transforma-se para atender ao desejo do turista.

O lugar assim inventado para e pelo turismo transforma-se no Outro, aquele desejado e esperado pelos turistas. Eles visitam, aceitam o proposto pelo receptivo, dele participam e, quando retornam aos seus lugares, é com o sentimento de terem conhecido um novo lugar, uma nova cultura. Será mesmo?

Os agentes locais assumem a função de construtores do objeto turístico na ânsia de agregar valor turístico aos lugares, aos bens imateriais e aos comportamentos locais, captando os desejos e as fantasias dos visitantes e gerando uma "cultura turística".

Ainda de acordo com Almeida (2003), a cultura turística, como produto de uma cultura pós-moderna, se realiza substancialmente no plano do simbolismo, isto é, os principais produtos ofertados e consumidos são imateriais, como por exemplo, a beleza, a tranquilidade, a história do lugar, o prazer de um encontro, de uma descoberta, entre outros.

Tanto a cultura turística como a cultura original das populações locais se metamorfoseiam durante o encontro entre elas: o turista, no desejo de realizar suas expectativas e fantasias de uma cultura turística, e as populações locais, que reduzem sua visibilidade uma vez que o destaque são seus atrativos turísticos e suas representações. Por isso mesmo, mantêm esses atrativos e representações e não medem esforços para que sejam apreciados nos seus aspectos de estética, distinção e singularidade.

Caberia aqui uma reflexão sobre o sentido da proximidade proposto por Bartholo (2008). Para o autor, a proximidade, que pode ser comparada à interação entre os povos contestada anteriormente por Araújo (1998), é muito mais do que espacial, há uma inversão do sentido topológico de proximidade. Bartholo (2008) afirma que com a recusa da relação vinculante entre o turista e o morador local (que ele figura na relação EU TU), não se nega apenas a alteridade do outro, mas também a oportunidade de afirmar-se perante o outro. Com isso, o autor responsabiliza tanto os viajantes como os locais de assumir uma atitude dialógica no encontro. 
Atitude que não poderá ser tomada diante de uma "coisificação" do outro ou do que pertence ao outro, mas sim por meio de um processo de interlocução.

Uma abertura dialogal para a vida vivida se dirige para os
imaginários da situação, não para as capturas conceituais pré-
concebidas. Não basta apenas encontrar um pseudo-outro que
se enquadre em minhas capturas conceituais. O que se requer
é disponibilidade e vulnerabilidade para imaginar-se no outro,
ampliando o senso de comunidade num encontro de um outro
que podia ser eu. Aceitar a contingência das linguagens, das
identidades e das comunidades e receber novas descrições da
realidade que podem alterar as nossas verdades provisórias.
Essa é a condição de possibilidade de se compartilhar
comunidades de sentido, de se permitir a si mesmo genuína
interlocução com sítios simbólicos de pertencimento. Pois os
sítios simbólicos de pertencimento “... não são espaços
geométricos euclidianos e vazios de sentido. Não são aqueles
'não-lugares' semelhantes às grandes estações ferroviárias ou
a supermercados da mega-máquina da sociedade econômica"
(BARTHOLO, 2008, p. 52).

Se tal atitude dialógica fosse tomada frente a essa nova demanda turística, o turista poderia vivenciar o lugar em contato direto, sem barreiras, com a população local, estabelecendo relações pessoais. Nas palavras de Fratucci (2000, p. 130), seria o fortalecimento do conceito do turismo enquanto "momento de encontro de alteridades, onde é possível a troca de experiências socioculturais e do enriquecimento pessoal [...], ou seja, o turismo acontecendo enquanto fenômeno sociocultural e não apenas como atividade econômica".

A produção do lugar turístico também se faz por meio das interações. Fratucci (2000) explica que para o turista essa experiência irá trazer um crescimento pessoal de descoberta de si e do outro e a satisfação de muitas expectativas, sonhos e ansiedades que o levaram a viajar. Para o morador local, a experiência da interação com o turista irá propiciar, além do seu crescimento pessoal interior, a consolidação da sua identidade com o seu lugar onde estão suas experiências vividas, reforçando sua noção de pertencimento e a consciência de todas as possibilidades do seu cotidiano, a sua dimensão de vida. O lugar turístico, então, passa a existir enquanto um espaço relacional entre turista e morador local. 
A alteridade foi aqui discutida tendo em vista a tendência atual de segmentação dos fluxos de demanda pelo turismo cultural e aumento do nível de exigência dos turistas, inclusive por esse segmento. Entende-se que a apropriação indiscriminada do legado cultural de uma população sem que se promova esse encontro dialógico que culmina em uma interpretação devida da cultura alheia, é uma apropriação exclusivamente mercantilista, utilitária e, portanto, prejudicial.

Retomando a questão da ressignificação do lugar onde as práticas turísticas se desenvolvem, cabe uma consideração de Paes (2008), que defende a existência de uma produção ideológica espacializada, onde ocorre a seleção e a valorização de identidades territoriais, bens materiais e expressões simbólicas, eleitos como patrimônio cultural.

Tal ideologia espacializada nos fornece uma nova interpretação da cultura pelas práticas do consumo de massa no território e legitima a mercantilização da cultura. Este universo material e simbólico da produção cultural do espaço tem se tornado objeto do olhar turístico, supervalorizando os bens de diferentes expressões culturais e fortalecendo a atratividade dos lugares.

Ainda de acordo com Paes (2008), identidades territoriais até então esquecidas pelos próprios agrupamentos culturais aos quais pertencem, emergem como objetos de consumo valorizados na mercantilização turística das paisagens, dos lugares e dos territórios, adquirindo novas dimensões econômicas, políticas e também culturais.

A supervalorização estética do lugar enquanto espaço cultural em detrimento do espaço vivido cotidianamente pelos habitantes, a espetacularização da identidade como uma imagem a ser vendida, e a apropriação de tradições na reprodução de festas e crenças como espetáculos agendados para altas temporadas tiveram um papel decisivo na refuncionalização do lugar para atender às demandas turísticas, alterando o seu significado cultural para a população local.

A identidade e o sentimento de pertencimento ao lugar se diluem no consumo cultural, na valorização estética e mercadológica, sendo priorizados os signos, os símbolos, os discursos e as imagens na construção de uma identidade distintiva como estratégia na venda turística dos lugares.

É necessário o aprofundamento de reflexões acerca das variadas estratégias de representação, valorização, apropriação e uso da cultura, hoje em processo de refuncionalização. Isso possibilitará a compreensão do 
modo como a mesma foi incorporada à esfera do consumo, agregando valor econômico aos lugares-símbolo de pertencimento de identidades territoriais e contribuindo na seleção de um conjunto de formas e expressões culturais que passaram a ser atrativas para o olhar turístico.

\title{
Considerações finais
}

Cabe reiterar nessas considerações finais a necessidade de reflexão ante a ressignificação da cultura pelo mercado turístico e suas implicações nos espaços relacionais e na autoafirmação identitária das sociedades incluídas nesse processo de mercantilização da cultura. E nessa reflexão, identificar em que medida a monetarização e espetacularização se retroalimentam como vetores de uma colonização da vida vivida por estruturas produtoras de experiências que se dizem "culturais".

Percebe-se que ao mesmo tempo em que populações tradicionais tentam manter sua cultura de acordo com padrões estéticos originais, ou por reagir às forças de mercado ou por aliar-se a ele na constituição de um produto cultural, apresentam força contrária que tende a impulsioná-la em busca da modernização. Esse conflito é compreensível, visto que a cultura é dinâmica e os lugares se globalizam na medida em que o mundo se globaliza em sua totalidade. As identidades dos grupos também não são estáveis, uma vez que diferentes contextos e temporalidades determinam essas identidades. Contudo, há de se ter consciência de que esse dinamismo deve acontecer de forma natural, sem que haja uma imposição da indústria cultural.

Costa (2010), ao tratar da necessidade da apreensão da concretude do fenômeno do turismo, faz a seguinte consideração:

\begin{abstract}
A dinâmica territorial e a revaloração paisagística propiciadas pelo turismo devem ser interpretadas a partir do entendimento da dialética de uma lógica global e de uma lógica local que criam e recriam formas, estabelecem novas estruturas, promovem a refuncionalização dos objetos e, no limite, correspondem ao desenrolar de um longo processo histórico (p.167).
\end{abstract}

O autor ainda sugere que ultrapassemos a "intensa superficialidade" de interpretação do mundo, de seus fenômeno e de sua lógica. Vale acrescentar que a compreensão dos processos globais está intimamente 
relacionada à própria compreensão da cultura, enquanto produto alvo de consumo e exploração midiática e do turismo.

Para Meneses (2004), a cultura é o resultado de uma construção coletiva, onde houve a junção de culturas diferentes e novas soluções para problemas cotidianos. O autor enfatiza a importância da reflexão sobre as formas de interpretação da cultura como patrimônio para uso turístico, permitindo problematizar o passado, contribuir com o conhecimento e fazer dessa reflexão, instrumento de inclusão social.

O interpretar (a cultura), segundo Meneses (2004, p.55), “é produzir um significado para as coisas que as pessoas veem e buscam usufruir prazerosamente nas suas vivências como turistas".

Ainda de acordo com o autor, para que haja perspectiva de um planejamento turístico que explore de maneira sustentável um atrativo cultural, é preciso uma intervenção prática reflexiva. E que assim, favoreça a democratização do conhecimento sobre o patrimônio cultural da comunidade, a orientação e a conscientização desse patrimônio de forma compreensível e ampliada; a racionalização do uso; o incentivo ao desenvolvimento da cidade, incluindo a comunidade na participação desse desenvolvimento; e a sensibilização para ações preservacionistas e de promoção da memória histórica local e regional, que também inclua toda sociedade participante.

Não é pretensão do presente artigo levantar os efeitos negativos do turismo que geram impactos na cultura das comunidades receptoras, nem tampouco condenar a modernização advinda com o desenvolvimento da atividade turística, visto que em qualquer sociedade, mesmo as mais tradicionais, isso é inevitável. O que se contesta aqui é o mau uso e apropriação indevida dos elementos simbólicos e identitários, na tentativa de gerar um produto comercializável que ressignifique a própria realidade vivida pelos atores sociais envolvidos, criando um novo valor. Talvez apenas a comunidade que construiu sua identidade, saiba o verdadeiro valor de seu legado cultural, pois ele é, por sua vez, de ordem simbólica, imaterial e só pode ser captado por outros através de representações.

Entende-se que a recuperação da memória coletiva, mesmo que seja para reproduzir a cultura local para os turistas, produz o desejo de afirmação da própria identidade e, num ciclo de realimentação, estimula a uma procura por recuperar cada vez mais seu próprio passado. Além disso, leva a comunidade ao conhecimento de seu patrimônio, conhecimento esse que conduz à valorização. 
Entende-se que o turismo com base na preservação da cultura, e não na sua exploração comercial, permite que a comunidade se engaje no processo de recuperação da memória coletiva, de reconstrução da história e de verificação das fontes, fortalecendo os seus sentidos e conexão com o espaço vivido, sua identidade cultural.

\section{A APROPRIAÇÃO DA CULTURA PELO TURISMO, A REVALORIZAÇÂO E A RESSIGNIFICAÇÃO DAS IDENTIDẢDES CULTURAIS}

Resumo: O presente artigo pretende abordar a apropriação da cultura pelo turismo, dando enfoque ao chamado culturalismo expresso na fragmentação da era pós-moderna. O turismo não será analisado apenas em sua dimensão material do espaço, mas como um fenômeno econômicocultural moderno dinamizado por uma sociedade de consumo. Sua produção, reprodução, fragmentação e homogeneização no/do espaço por meio das novas espacialidades da vida social, material e simbólica, por vezes produzem lugares turísticos subordinados aos atores hegemônicos, gerando problemas de diversas ordens. $\mathrm{O}$ mercado turístico divulga $\mathrm{e}$ desperta a busca por novas experiências culturais, alavancando esse segmento e alterando o perfil do turista, na medida em que as populações receptoras também se alteram, se adaptam. $\mathrm{O}$ mau uso e a apropriação indevida dos elementos simbólicos e identitários das populações receptoras constituem uma tentativa de gerar produtos comercializáveis que ressignifiquem a própria realidade vivida pelos atores sociais envolvidos, criando um novo valor, um novo olhar, tanto das populações locais sobre si mesmas, como do turista sobre a cultura alheia. O legado cultural, assim transformado em produto para o consumo, perde seu significado autêntico. A cultura deixa de ser importante por si mesma e passa a ser importante por suas implicações econômicas.

Palavras chave: Cultura, identidade, turismo, mercado, consumo.

\section{THE APPROPRIATION OF CULTURE BY TOURISM, THE REVALUETION AND RESIGNIFY OF CULTURAL IDENTITIES}

Abstract: This article intends to broach the appropriation of culture for tourism, focusing on the called culturalism expressed in this fragmentation 
of the postmodern era. Tourism will not be analysed only in its material dimension of the space, but as a modern, economic and cultural phenomenon spurred by a consumer society. Its production, reproduction, fragmentation and homogenization in / of space through new spatiality of social, material and symbolic life, sometimes produce tourist places which are subordinated by hegemonic actors, creating problems of several orders. The tourist market publishes and awakens to the search for new cultural experiences, leveraging this segment and changing the tourist's profile, in so far as the receivers populations also change, they adapt. The misuse and misappropriation of symbolic and identity elements of receivers populations constitute an attempt to generate marketable products that resignify the own lived reality by social actors involved, creating a new value, a new look, both local people about themselves as the tourist about the culture of the others. The cultural legacy, thus transformed in a product for consumption, it loses its authentic meaning. The culture stops to be important in itself and becomes to be important for its economic implications.

Key words: Culture, identity, tourism, market, consumption.

\section{BIBLIOGRAFIA}

ALMEIDA, Maria Geralda de. (2004) Desenvolvimento turístico ou desenvolvimento local? Algumas reflexões. In: ENTBL - Planejamento para o desenvolvimento local,, Curitiba. Anais... Curitiba.

. (2003) Lugares Turísticos e a Falácia do Intercâmbio Cultural. In: ALMEIDA, M. G. [org.]. Paradigmas do Turismo. Alternativa. Goiânia, PP 11-18.

(1998) Refletindo sobre o lugar turístico no global. In: Turismo com ética. CORIOLANO, Luzia Neide M. T. (org.). UECE. Fortaleza, pp. $122-131$.

ARAÚJO, Paulo Sérgio Oliveira de. (1998) Desenvolvimento do turismo e população local. In: Turismo com ética. CORIOLANO, Luzia Neide M. T. (org.). UECE. Fortaleza. pp. $362-373$.

BARRETTO, Margarita. (2000) Turismo e legado cultural: as possibilidades do planejamento. Papirus. Campinas.

BARTHOLO, Roberto. (2008) Sobre o sentido da proximidade: implicações para um turismo situado de base comunitária. In: 
BARTHOLO, Roberto et al. (orgs.). Turismo de base comunitária: diversidade de olhares e experiências brasileiras. COPPE / UFRJ. Rio de Janeiro, pp. 45 - 54.

BENI, Mário Carlos. (2003) Análise estrutural do turismo. 8. ed. Editora Senac. São Paulo.

BEZERRA. Amélia C. Alves. (2007) Festa e Identidade: A busca da diferença para o mercado de cidades. In: ARAÚJO, F. G. B., HAESBAERT, Rogério; ARAÚJO, Frederico G. B. de (orgs.). Identidades e Territórios: questões e olhares contemporâneos. 1 ed. Access. Rio de Janeiro, pp. $69-$ 92.

BUSTOS CARA, Roberto. (1996) El turismo y los processos de transformación territorial. In: RODRIGUES, Adyr A. B. (orgs.). Turismo e Geografia: reflexões teóricas e enfoques regionais. Hucitec. São Paulo.

CHAVEIRO, Eguimar Felício. (2008) A cultura como patrimônio e a vida como cultura: disputas de sentidos na Cidade de Goiás - um patrimônio da humanidade. Revista OLAM, Ciência e Tecnologia, ano 8, vol. 8, n. 1. Rio Claro: pp. $122 \quad-\quad 36 . \quad$ Disponível em: $<$ http://www.periodicos.rc.biblioteca.unesp.br/index.php/olam/ article/viewArticle/1238>. Acesso em $16 \mathrm{dez} 2010$.

CLAVAL, Paul. (2008) Uma, ou Algumas, Abordagem (ns) Cultural (is) na Geografia Humana? In: SERPA, Ângelo (org.). Espaços Culturais: vivências, imaginações e representações. EDUFBA. Salvador, pp. 15 - 29. COSTA, Everaldo Batista da. (2010) A Concretude do Fenômeno Turismo $e$ as Cidades-Patrimônio-Mercadoria: uma abordagem geográfica. Livre Expressão. Rio de Janeiro.

FRATUCCI, Aguinaldo César. (2000) Os lugares turísticos: territórios do fenômeno turístico. Revista GEOgraphia, Ano. II, n. 4, pp. 121 - 133.

HAESBAERT, Rogério. (2007) Identidades territoriais: entre a multiterritorialidade e a reclusão territorial [ou: do hibridismo cultural à essencialização das identidades]. In: ; ARAÚJO, Frederico G. B. de. Identidades e Territórios: questões e olhares contemporâneos. $1 \mathrm{ed}$. Access. Rio de Janeiro, pp. 33 - 55.

IRVING, Marta de Azevedo. (1998) Turismo e ética: premissa de um novo paradigma. In: Turismo com ética. CORIOLANO, Luzia Neide M. T. (org.). UECE. Fortaleza, pp. $32-42$.

MENESES, José Newton Coelho. (2004) História e Turismo Cultural. Autêntica. Belo Horizonte. 
PAES, Maria Tereza Duarte. (2008) Patrimônio cultural, turismo e identidades territoriais: um olhar geográfico. In: BARTHOLO, Roberto et al. (orgs.). Turismo de base comunitária: diversidade de olhares $e$ experiências brasileiras. COPPE / UFRJ. Rio de Janeiro, pp. $162-176$. 